\title{
Case-control Study on Related Factors of Alzheimer's Disease
}

\author{
Zhenghai Sun, Yunfeng Han, Fengwu Yan, Na Wang, \\ Wenlin Wang, Jingwen Meng, Huimin Han, Jianzhong Li \\ Qiqihar Medical University, \\ Qiqihar 161006, China
}

\begin{abstract}
Objective To investigate the related risk factors and protective factors of Alzheimer's disease(AD) to provide references for its etiologic study, early prevention and intervention Methods 1:1case-control study was conducted, the study included 87 patients of clinically diagnosed AD from the city proper of Qiqihar Heilongjiang province. According to the same community , sex, age $( \pm 3 y e a r s)$,and the educational level. collect data and univariate and multiple conditional Logistic regression analysis. Results Single factor analysis showed that professional, history of hyperlipidemia, physical exercise, housework, Recreational activities, intellectual activity, personality, often high fat diet and other factors through analysis and comparison of eight statistically significant $(P$ values were $<0.05)$; multiple conditional Logistic regression analysis showed that professional $(O R=0.109,95 \%$ CL: $0.020 \sim 0.592)$, history of hyperlipidemia (OR $=5.769,95 \%$ CL: $1.410 \sim$ 23.608), intellectual activity (OR $=0.130,95 \%$ CL: 0.034 0.502), high fat diet (OR = 3.217, 95\% CL: $1.081 \sim 9.568)$ and AD disease was closely related. Conclusion professional, history of hyperlipidemia, intellectual activity, high fat diet were closely related with $A D$, which engaged in mental, intellectual activity were AD protective factors, while engaged in manual labor, history of hyperlipidemia, high fat diet were Alzheimer's disease risk factors.
\end{abstract}

Keywords: Alzheimer's disease(AD), factor

\section{INSTRUCTION}

Also known as Alzheimer's disease dementia (Alzheimer's diseases, $\mathrm{AD}$ ) is the degeneration of the nervous system caused by cerebral cortex senior dysfunction of mental activities, is acquired, comprehensive, sustainable intellectual disability syndrome, is a major type of old age dementia. As reported at home and abroad, the Prevalence of AD has increased trend, Its prevalence rate is $4 \%-9 \%$ among the people more than 65-year-old [1-2], AD has become one of the main diseases endangering health of the elderly, will Increase the burden of social and economic development and the elderly health care. Therefore, to explore the related factors of AD illness of the disease prevention and early intervention is necessary. In AD patients as the research object, this study adopts 1:1 case-control study, discusses the AD related risk factors and protective factors, aimed at making effective preventive strategies and measures to provide reference for the disease.

\section{OBJECTS AND METHODS}

\section{A. Object of Study}

Selection of Qiqihar city of clinically confirmed 87 cases of patients with AD group, the diagnosis of dementia conform to the fourth edition of the diagnostic and statistical manual of mental disease (DSM - IV)[3], the diagnosis of $\mathrm{AD}$ by reference to the neurology, language barriers and stroke - senile dementia and related disorders learn standard (NINCDS ADRDA) [4]. Cases the inclusion criteria: (1) age 60 or higher; (2) Conform to the above diagnosis standard; (3) or reliable person willing to participate. Of $1: 1$ case-control study for diagnosis of AD patients in the control group included in the standard is: from the cases with community residents, the principle for the cases with same gender, culture degree, age group $(+/-3$ years of age) of the cognitive dysfunction and severe cerebrovascular and other diseases of the central nervous system of the residents, a reliable person or person willing to participate in investigation and sign an informed consent.

\section{B. Survey Method}

By trained and the questionnaire survey was conducted among researchers about the object of study and mental status of Chinese revision simple intelligence scale (mini - getting the state examination, MMSE) [5] measurement, questionnaire according to various etiology hypothesis and possible risk factors, including social demographic data, past medical history and history of present illness, family history, personal life history and social activities, environmental exposure history five group 42 survey factors, such as the elderly health condition and various related factors to do a full investigation.

\section{The Quality Control}

Investigation team composed of neurology, neuropsychological and psychiatrists and master relevant knowledge and have a senior medical students clinical skills. Investigation before all investigators to unified training and doing experiments, the correct understanding and using the survey tool, the scale consistency check Kappa value was 0.83 0.83 . All the survey data in the inspection shall verify that day, the missing items and fill in the wrong data timely notify the investigators to supplement the correction, and archiving. 


\section{Statistical Analysis}

All data entry, after unified coding using EpiData3.1 software using SAS9.13 1:1 matching single factor analysis, will filter out there are statistically significant factors for conditional Logistic regression model fitting, multi-factor analysis.

\section{RESULTS}

\section{A. General Cases}

Male 35 cases, 52 cases, women age range from 60 to 90 years, mean age $75.76+/-7.22$ years old; Men in the control group 35 cases, women 52 cases, age range of 60 89 years, mean age $75.37+/-7.50$ years old. Two groups of average age is no statistically significant difference $(\mathrm{t}=$
$0.34942, \mathrm{P}=0.34942)$. The research object of cultural degree: illiteracy $(48.3 \%)$, primary school $(25.3 \%)$, middle (24.1\%), junior college $(2.3 \%)$.

\section{$B$. $A D$ relevant results}

AD illness related single factor analysis of 87 gained by the research object in addition to gender, age, culture level three factors all factors in single factor analysis, the results showed that occupation, a history of hyperlipidemia, physical activity, housework, recreational activities, intellectual activity, eight factors such as personality, often a high-fat diet by analysis and comparison was statistically significant $(\mathrm{P}<0.05)$. (in table 1$)$.

TABLE 1. AD RELEVANT RESULTS OF THE SINGLE FACTOR ANALYSIS

\begin{tabular}{|c|c|c|c|c|c|}
\hline ADrelated factors & & Casegroup(\%) & control group $(\%)$ & $\chi^{2}$ & $\mathrm{P}$ \\
\hline \multirow[t]{2}{*}{ Professional } & Mental work & $13(14.94 \%)$ & $28(32.18 \%)$ & 7.18 & 0.007 \\
\hline & Manual labor & $74(85.56 \%)$ & $59(67.82 \%)$ & & \\
\hline Historyofhyperlipidemia & no & $68(78.16 \%)$ & $79(91.80 \%)$ & & \\
\hline \multirow[t]{3}{*}{ Physical exercise } & never & $15(17.25 \%)$ & $4(4.60 \%)$ & 12.5882 & 0.0018 \\
\hline & sometimes & $28(32.18 \%)$ & $18(20.69 \%)$ & & \\
\hline & often & $44(50.57 \%)$ & $65(74.71 \%)$ & & \\
\hline \multirow[t]{3}{*}{ housework } & never & $30(34.48 \%)$ & $15(17.24 \%)$ & 6.80 & 0.033 \\
\hline & sometimes & $21(24.14 \%)$ & $28(32.18 \%)$ & & \\
\hline & often & $36(41.38 \%)$ & $44(50.57 \%)$ & & \\
\hline \multirow[t]{3}{*}{ Recreational activities } & never & $29(33.33 \%)$ & $16(18.39 \%)$ & 10.170 & 0.0062 \\
\hline & sometimes & $32(36.78 \%)$ & $25(28.74 \%)$ & & \\
\hline & often & $26(29.89 \%)$ & $46(52.87 \%)$ & & \\
\hline \multirow[t]{2}{*}{ Intellectual activitiy } & has & $23(26.44 \%)$ & $48(55.17 \%)$ & 14.870 & 0.0001 \\
\hline & no & $64(73.56 \%)$ & $39(44.83 \%)$ & & \\
\hline \multirow[t]{2}{*}{ personality } & Extrovert & $42(48.28 \%)$ & $64(73.56 \%)$ & 15.1138 & 0.0005 \\
\hline & Introvert & $16(18.39 \%)$ & $3(3.45 \%)$ & & \\
\hline \multirow[t]{2}{*}{ high-fat diet } & yes & $30(34.48 \%)$ & $18(20.69 \%)$ & 4.1429 & 0.0418 \\
\hline & no & $57(65.52 \%)$ & $69(79.31 \%)$ & & \\
\hline
\end{tabular}

\section{AD illness related multifactor conditional Logistic} regression analysis

The single factor analysis to obtain the significant meaning of eight variables into the multifactor conditional logistic regression model fitting, for its further screening, from to rule out confounding factors of multifactor conditional logic analysis results can be seen, professional $(\mathrm{OR}=0.109$, $95 \%$ ci: $0.020 \sim 0.592)$, the history of hyperlipidemia $(\mathrm{OR}=$ $5.769,95 \%$ ci: $1.410 \sim 23.608)$, mental activities $(\mathrm{OR}=$
$0.130,95 \%$ ci: $0.034 \sim 0.502)$, high fat diet $(\mathrm{OR}=3.217$, $95 \%$ ci: $1.081 \sim 9.568$ ) closely associated with AD illness. Which is engaged in mental Labor, intellectual activity is the protection factor in senile dementia disease, and engaged in manual Labor, has a history of hyperlipidemia, high fat diet is a risk factor for dementia disease (in table 2). 
TABLE 2. AD ILLNESS RELATED MULTIFACTOR CONDITIONAL LOGISTIC REGRESSION ANALYSIS RESULTS

\begin{tabular}{|c|c|c|c|c|c|c|}
\hline Variable & $\mathrm{DF}$ & \multicolumn{2}{|c|}{$\begin{array}{l}\text { Parame- } \\
\text { ter Esti- } \\
\text { mate }\end{array}$} & \multicolumn{2}{|c|}{$\begin{array}{l}\text { Standard } \\
\text { Error }\end{array}$} & Chi-Square \\
\hline $\begin{array}{l}\text { Professional } \\
\text { Historyof }\end{array}$ & 1 & \multicolumn{2}{|c|}{-2.22094} & \multicolumn{2}{|c|}{0.86573} & 6.5813 \\
\hline $\begin{array}{l}\text { hyperlipide- } \\
\text { mia }\end{array}$ & 1 & \multicolumn{2}{|c|}{1.75258} & \multicolumn{2}{|c|}{0.71890} & 5.9431 \\
\hline $\begin{array}{l}\text { Physical ex- } \\
\text { ercise }\end{array}$ & 1 & \multicolumn{2}{|c|}{0.99906} & \multicolumn{2}{|c|}{0.55239} & 3.2711 \\
\hline housework & 1 & \multicolumn{2}{|c|}{0.13160} & \multicolumn{2}{|c|}{0.31593} & 0.1735 \\
\hline $\begin{array}{l}\text { Recreational } \\
\text { activities }\end{array}$ & 1 & \multicolumn{2}{|c|}{-0.35657} & \multicolumn{2}{|c|}{0.36518} & 0.9534 \\
\hline $\begin{array}{l}\text { Intellectual } \\
\text { activities }\end{array}$ & 1 & \multicolumn{2}{|c|}{-2.03723} & \multicolumn{2}{|c|}{0.68765} & 8.7770 \\
\hline personality & 1 & \multicolumn{2}{|c|}{-0.32924} & \multicolumn{2}{|c|}{0.43901} & 0.5624 \\
\hline high-fat diet & 1 & \multicolumn{2}{|c|}{1.16835} & \multicolumn{2}{|c|}{0.55615} & 4.4133 \\
\hline Variable & \multicolumn{2}{|c|}{$\operatorname{Pr}>$ ChiSq } & \multicolumn{2}{|c|}{$\begin{array}{l}\text { Hazard } \\
\text { Ratio }\end{array}$} & \multicolumn{2}{|c|}{$\begin{array}{l}\text { 95\% Hazard Ratio } \\
\text { Confidence Limits }\end{array}$} \\
\hline Professional & \multicolumn{2}{|c|}{0.0103} & \multicolumn{2}{|c|}{0.109} & 0.020 & 0.592 \\
\hline $\begin{array}{l}\text { Historyof } \\
\text { hyperlipide- } \\
\text { mia }\end{array}$ & \multicolumn{2}{|c|}{0.0148} & \multicolumn{2}{|c|}{5.769} & 1.410 & 23.608 \\
\hline $\begin{array}{l}\text { Physical ex- } \\
\text { ercise }\end{array}$ & \multicolumn{2}{|c|}{0.0705} & \multicolumn{2}{|c|}{2.716} & 0.920 & 8.018 \\
\hline housework & \multicolumn{2}{|c|}{0.6770} & \multicolumn{2}{|c|}{1.141} & 0.614 & 2.119 \\
\hline $\begin{array}{l}\text { Recreational } \\
\text { activities }\end{array}$ & \multicolumn{2}{|c|}{0.3289} & \multicolumn{2}{|c|}{0.700} & 0.342 & 1.432 \\
\hline $\begin{array}{l}\text { Intellectual } \\
\text { activities }\end{array}$ & \multicolumn{2}{|c|}{0.0031} & \multicolumn{2}{|c|}{0.130} & 0.034 & 0.502 \\
\hline personality & \multicolumn{2}{|c|}{0.4533} & \multicolumn{2}{|c|}{0.719} & 0.304 & 1.701 \\
\hline high-fat diet & \multicolumn{2}{|c|}{0.0357} & \multicolumn{2}{|c|}{3.217} & 1.081 & 9.568 \\
\hline
\end{tabular}

\section{DisCUSSION}

In this study with the community, gender, age, cultural level as the matching conditions, with 1:1 case-control study method, all the 87 cases of patients diagnosed with $\mathrm{AD}$ carried out a case-control study and control the effects of confounding factors such as gender, age. Single factor analysis results showed that professional, history of hyperlipidemia, physical exercise, housework, recreational activities, intellectual activity, eight factors such as personality, often a high-fat diet by analysis and comparison have statistical significance. To exclude the interference of confounding factors other than the matching conditions,put the eight significant meaning variables obtained in the single factor analysis into the multifactor conditional logistic regression model fitting, for its further screening, multi-factor analysis results showed that professional, the history of hyperlipidemia, intellectual activity, high fat diet and $\mathrm{AD}$ is more close to the sick.Engage in mental and intellectual activity is the protective factors for the senile dementia disease. while engaged in manual labour, a history of high cholesterol, high fat diet is senile dementia risk factor for disease.

Required by the complex work and career intelligence and cognitive ability increases the brain's cognitive reserve, the AD plays a protective role, low-skilled occupations, unemployed may be a risk factor for AD. Relevant professional relationship with the senile dementia, the domestic reports are v'ery few, this study result is consistent with the foreign reports, the results of a prospective cohort study found that the simple labor type of work or career is a risk factor for AD (RR > 1, PARP > 50\%) [6]. Kukull [7] reported prospective cohort study of 2345 cases, AD114 example, observation of 10590 cases, found the unskilled and housekeeping worker $\mathrm{AD}$ prevalence 2 times higher than that of professional workers. Saczynski etc. [8] research shows that engaged in the professional nature of the decline has obvious correlation with cognition. This study found that mental activity for AD have a protective effect, in line with domestic related research, such as Ren Qingtao's [9] study found that the prevalence of mental activity group AD lower than the group intelligence activities, and intellectual activity group $\mathrm{AD}$ onset age later than no intellectual activity group $(\mathrm{P}<0.01)$, that intellectual activity helps to reduce the risk of suffering from $\mathrm{AD}, \mathrm{AD}$ may have a protective effect. Katzman has (1993) that the AD change prompts the 
brain cognitive function neocortex synaptic density change, education and sustained intellectual activities to promote the new brain cortex synaptic density increase, improve the brain reserves, so as to delay Alzheimer disease (AD) [10]. This study found that a history of high cholesterol and high fat diet is a risk factor for AD illness, a large number of animal experiments and epidemiological data indicate that excessive intake of saturated fat and cholesterol may increase the risk of dementia. In the Wang Chunyu etc. 's [11] case control study of AD patients, found that cholesterol and lipid levels in patients with $\mathrm{AD}$ is significantly higher than the control group. Foreign scholars also reported that blood cholesterol levels associated with the severity of the AD. Age spots the primary components of A beta from amyloid precursor protein (APP), serum cholesterol by influencing the protein of different transportation way indirectly affect metabolism of APP, to intervene in A beta, and at the same time, A lot of cholesterol can cause beta-secretase cracking product increase, thus affecting the production of A beta. Multi-factor analysis of meaningless and single factor analysis has significant meaning of physical exercise, housework, recreational activities, such as personality factors, existing literature on its relevance to $\mathrm{AD}$ illness, pending further study.

Fund Project: This work is supported by the Heilongjiang provincial health department project(2012-344)

\section{REFERENCES}

[1] Zhang Mingyuan. 2003 .Old age dementia epidemiological survey . Practical geriatric medicine.10 (3) : 97-98

[2] Zhou Bin, Hong Jin, Huang Maosheng, etc. 2001.Shanghai urban and rural population dementia prevalence survey. Chinese journal epidemiology. 22 (5) : 368-371.

[3] American Psychiatric Association Diagnostic and statistical of mental disorders . 1994.4th ed .Washington DC: American Psychiatric Association.

[4] Mckhann G.Drachmate D.Folstein M.et al .1984.Clinical diagnosis of Alzheimer's disease: report of the NINCDS-ADRDA Work Group under the auspices of Department of Heath and Human Services Task Force on Alzheimer's Disease.Neurology.34(7):939-944.

[5] Xu Xianhao,Peng Dantao. 2007.neuropsychological scale test guide . Beijing: Beijing union medical university press.

[6] Hande Harmanci,Murat Emre,et al.2003.Risk Factors for Alzheimer's disease:A Population-Based Case-Control Study in Istanbul,Turkey. Alzheimer Dis Assoc Disord,17(3):139-145

[7] Kukull WA. 2002.Occupational factors and Alzheimer's disease. Neurobiology of Aging.23(1S):S6

[8] Saczynski JS, Pfeifer LA, Masaki K, et al. 2006.The effect of social engagement on incident dementia: the Honolulu-Asia Aging Study. Am J Epidemiol.163(5):433-440

[9] Ren Qingtao ,Lu Yingzhi, Tian Mingping, etc. 2003. Competitive intelligence type of leisure activities affect Alzheimer's disease. Chinese journal of psychiatry. 5 (36) : 109-112.

[10] Katzman R.1993.Education and the prevalence of dementia and Alzheimer'sdisease. Neurolgy. 43:13 20.

[11] Wang Chunyu, Qian Caiyun, Fang Yingying, etc. 2006. Alzheimer's disease serum cholesterol, blood lipid, folic acid and b12, and thyroid hormone changes of clinical research . Chinese journal of gerontology. $26(7): 873-875$ 